only 33 to nitrogen, phosphorus, arsenic, antimony, bismuth, carbon and silicon. Volume 2 deals with metals.

The book makes extremely interesting reading. The authors have thought deeply about all aspects of the material they present, and have tried with much success to relate everything to fundamental principles. Electronic structure of atoms provides the framework; detailed changes in properties such as the variation of ionization energy with atomic number are illuminatingly described; concepts of energetics are constantly referred to; the mechanisms of the reactions of transition elements are discussed at length; modern ideas about the electronic spectra and magnetic properties of transition elements are introduced; and there is a particularly valuable chapter on band theory in solids. Throughout the book, very few facts are presented without a gloss correlating them with some model or concept.

With all these excellent features, it may seem strange to confess to a slight feeling of dissatisfaction on reading the book. This is not due to the very few factual slips, such as the perpetuation of the myth of the self-ionization of $\mathrm{SO}_{2}$. In places the unconventional arrangement has disadvantages; and it is a pity that silicon appears in Volume 1 and germanium, tin and lead in Volume 2. The usefulness of the terms ' $A$-group' and ' $B$-group' metals in a modern text is also questionable. But perhaps the most serious criticism is that the authors have in places allowed their very proper enthusiasm for principles to prevent them from giving a simple account of how compounds are made and of what sort of chemical individuals they are. Thus the book is surprisingly deficient in information on some topics; furthermore, the arrangement makes it hard to find some of the information that is included. As a consequence, it is not an ideal book to be used as the sole inorganic text in a crowded degree course. On the other hand, it is essential and most stimulating reading for anyone seriously interested in the application of physical principles to inorganic systems.

E. A. V. EBsworth

\section{INSIGHTS IN CHROMATOGRAPHY}

\section{Dynamics of Chromatography}

By J. Calvin Giddings. Part 1: Principles and Theory. Pp. xii +323 . (London: Edward Arnold (Publishers), Ltd.; Now York: Marcel Dekker, Inc., 1965.) 90s. net. Chromatography is different things to different people. To the majority of workers in chemical and biological sciences it is a rapid, simple and elegant answer to a practical problem. As one may distil or crystallize with littlo knowledge of the associated fundamentals, so one may separate and identify with no background of the theory of chromatography. Trial and error, based on analogy with previously successful methods, is the common approach in a new situation. It must not, however, be forgotten that the first dramatic developments in chromatography came as a result of the theoretical treatment of Martin and Synge, which gave an insight into the achievement and potential of the method. Dr. Giddings writes of the work, in which he has been very active, of replacing the early crude but stimulating models with a more powerful and simple approach, based on the statistics of molecular movement.

To Dr. Giddings, chromatography is the interaction of flow, diffusion and other processes, resulting in the evolution and eventual separation of component zones. Analyses of zone migration, zone spreading, diffusion and kinetics and the achievement of separations are clear, critical and readable. In a field hitherto rich in the wisdom of hindsight, it is encouraging to read that in the author's opinion chromatographic theory has now outreached the state of knowledge of the columns them selves and that the limit of theoretical accuracy is determ- ined by the precision with which the structural and adsorptive features of the chromatographic medium can be described. The chapter on packing structure and flow dynamics, although acknowledging the need to use simple models and empirical parameters, leads to a surprising and significant comparison of the potentials of gas and liquid chromatography. Many topies are discussed in a way that sticks in the mind as, for example, the relevance and re-interpretation of the theoretical plate concept, and gradients and resolution.

This work is an attempt to present the common foundations of the many forms of chromatography in a reasonably exact way. Parts of it will prove indigestible to the nonmathematical chromatographer. 'They are clearly indicated, and in general are not absolutely essential to a good understanding. On the whole, the treatment is more immediately relevant to the gas chromatographer, but it can be read with profit by anyone with an interest in "whys and wherefores".

The book is well produced at a reasonable price. It is the first of three volumes, the second of which will deal with gas chromatography and the third with liquid chromatography. If the standard is maintained, it will be a valuable series.

J. E. ScotT

\section{ANALYTICAL ION EXCHANGE}

\section{Analytical Applications of Ion Exchangers}

By J. Inczédy. Translatod by A. Páll. English translation edited by M. Williams. Edited by I. Buzás. Pp. xi +443 . (London and New York: Pergamon Press, Ltd., 1966.) 105s. net.

Is the relatively short history of ion-exchange resins, developments have occurred so rapidly that a monograph which surveys any area of their application is particularly welcome. This book was first published in Hungarian in 1962 , and brought up to date the theory and practice of ion exchangers in the analytical field. The early chapters are devoted to a brief historical introduction and to a survey of the basic physical chemistry of exchange reac. tions from the viewpoints of equilibrium, selectivity and kinetics. Next there is a section on the theory and practice of ion-exchange columns. From Chapter 6 onwards the book deals with applications in quantitative inorganic analysis; chromatographic separations; redox processes; organic chemical and biochemical analysis; the collection of physico-chemical data (ion valency, ion activity, complex stability and dissociation of electrolytes); and the purification of chemicals. Liquid ion-exchangers and ion-exchange membranes are also discussed. One feature of the book is the very full bibliography given at the end of each chapter. The author and translators have completed an excellent task, and the book can be recommended strongly to all interested in the science and technology of ion exchange.

R. M. BARRER

\section{CLAY}

\section{Clays and Clay Minerals}

Edited by W. F. Bradley and S. W. Bailey. (Proceedings of the Thirteenth National Conference conducted by the Clay Minerals Society, Madison, Wisconsin, October 5-8, 1964.) Pp. ix + 453. (London and Now York: Pergamon Press, Ltd., 1966.) 140s. net.

Since the sixth Conference on Clays and Clay Minerals, the proceedings have been published as monographs in the Earth Science Series. The present volume-Monograph No. 25-contains the proceedings of the thirteenth Conference conducted by the newly formed Clay Minerals Society. This and future conferences will be numbered 